Etxebarria Madinabeitia, Izaskun.

Doctorando de la Facultad de Bellas Artes de la Universidad Politécnica de Valencia.

Dpto. Escultura, Laboluz.

\title{
La política cultural desde dos enfoques divergentes: la cultura como lo común, la cultura como modelo productivo competitivo.
}

\section{Cultural politics from two divergent approaches: culture as the common, culture as a competitive production model.}

\author{
TIPO DE TRABAJO:
}

Póster.

PALABRAS CLAVE:

Cultura, procomún, espacio públco, esfera pública, modelo productivo competitivo.

KEY WORDS:

Culture, commons, public space, public sphere, productive model.

RESUMEN.

Este es un estudio comparativo entre dos modelos en política cultural. El primero propone la cultura como lo común en un sentido general global que se acerca hacia un modelo para contextos locales. Se desarrolla la primera parte del libro "Cultura Libre de Estado" (2016) de Jaron Rowan, a través de cuatro mapas conceptuales interrelacionados: "La Cultura como problema, como derecho y como recurso", "La Cultura como lo público, lo privado y lo común", "Las políticas del acceso" y "El procomún, o las formas del común situadas".

El segundo plantea un modelo competitivo de la cultura desde el enfoque productivo en un contexto autonómico en relación a un contexto nacional. Analizamos la propuesta marco presentada en el Plan Estratégico de la Cultura (PLEC) desde el documento Propuestas programáticas para un plan estratégico de la cultura encargado a Econcult por parte de la Generalitat Valenciana en 2016, cuyo éxito radica en un cambio del modelo de bienestar al modelo competitivo de la cultura para la consecución de ciertos objetivos derivados de "satisfacer los derechos culturales de la ciudadanía" a través de la política cultural propuesta, para transformar así, la realidad en la que se sitúa el ecosistema cultural valenciano.

\section{ABSTRACT.}

This is a comparative study between two models in cultural politics. The first proposes culture as the common in a general global sense that approaches a model for local contexts. The first part of Jaron Rowan's book "Free Culture of State" (2016) is developed through four interrelated conceptual maps: "Culture as a problem, as a right and as a resource", "Culture as the public, the private and the common" and "Access policies "and finally, "Commons, or common forms situated".

The second poses a competitive model of culture from the productive approach in an autonomous context in relation to a national context. We analyze the framework proposal presented in the Strategic Plan of Culture (PLEC) from the document Programmatic proposals for a strategic plan of the culture commissioned to Econcult by the Generalitat Valenciana in 2016, whose success lies in a change from the Welfare model to Competitive model of culture for the achievement of certain 
objectives derived from "satisfying the cultural rights of citizenship" through the proposed cultural policy, thus transforming the reality in which the valencian cultural ecosystem is located.

\section{CONTENIDO}

\section{INTRODUCCIÓN.}

A continuación, se detallan dos enfoques de política cultural: la cultura como bien común y la política cultural como modelo competitivo. Se presentarán gráficamente los desarrollos de ambos planteamientos para poder interrelacionarlos y ver sus aspectos de mayor interés, así como sus deficiencias y peligros.

\section{LA CULTURA COMO LO COMÚN.}

Cultura Libre (Rowan, 2016) analiza la cultura desde diversos enfoques: por un lado, la cultura como problema, como derecho, como recurso y como bien común; por el otro, la cultura como lo público, lo privado y lo común.

Dentro de lo público distingue lo estatal y lo no estatal y establece sus límites y potencias. Como límites define: su deber de hablar, interpelar y mostrarse accesible; no poder permitirse la hiperespecialización; y no poder ser experimental ni innovador. Como potencias identifica: un sistema de instituciones, espacios, recursos y agentes; aquello que da voz a distintas comunidades para que éstas puedan producir relatos colectivos; las identidades compartidas; y lo abierto, transitable y desbordable.

En lo público estatal diferencia cinco modelos: la gestión pública, la cogestión híbrida, la gestión cívica, la gestión colaborativa y la gestión comunitaria o común. En lo público no estatal presenta sus agentes como asociaciones, organizaciones de vecinos, colectivos y ONG-s. Sus características son el trabajo voluntario no remunerado, las garantías de acceso, la pluralidad, la calidad y la autonomía en contenido y enfoque.

El paradigma de lo común aparece como el nuevo paradigma de la propiedad. Sus características son: el no universalismo; el particularismo radical; no ser de interés general; tener mecanismos claros de entrada y salida; y distribuir responsabilidades sobre su gestión. Las infraestructuras y los equipamientos son bienes comunes que pertenecen a toda la ciudadanía que se comprometa en su gestión.

Las instituciones se consideran infraestructuras del común donde la ciudadanía consume y produce su propia cultura. Esta cultura es experimental, genera pensamiento y espacio crítico e implica distribución del poder y antagonismo. En consecuencia, produce empoderamiento de la ciudadanía y cohesión de las comunidades, aunque también conflicto, resistencias y pensamiento crítico, además de la puesta en crisis de la propiedad privada.

\section{EL MODELO CULTURAL COMPETITIVO.}

El desarrollo económico del PLEC 2016-2020 consiste en pasar del Modelo de bienestar al Modelo competitivo (Raussell, 2017):

A. Modelo de bienestar: La cultura incrementa la utilidad social de una comunidad, pero en términos de coste de oportunidad supone una carga neta para garantizar su provisión desde una perspectiva transformadora. La expansión está determinada por las condiciones de provisión de otros servicios públicos (sociales, sanitarios, educativos, etc.)

B. Modelo competitivo: La cultura es un sector más. Así, los cambios en el tamaño de la industria creativa tienen efectos sobre el conjunto de la economía, pero en proporción a su tamaño, y es estructuralmente neutral sobre la dinámica global. Los efectos sobre la renta, la productividad y el bienestar no son diferentes de los de cualquier otro sector. En términos de políticas públicas merece o desmerece las mismas ayudas que el resto de las actividades productivas.

La política cultural se plantea como la satisfacción de los derechos culturales de la ciudadanía. Su objetivo es transformar la realidad en la que se sitúa el ecosistema cultural valenciano, mediante el desarrollo de la expresión, la participación y la construcción de las identidades individuales y colectivas. La planificación cultural es la estrategia para coparticipar en el cambio de modelo productivo, que apuesta por una mayor innovación y productividad para conseguir valor añadido y puestos de trabajo. 
La política cultural desde dos enfoques divergentes: la cultura como lo común, la cultura como modelo productivo competitivo. III CONGRESO INTERNACIONAL DE INVESTIGACIÓN EN ARTES VISUALES :: ANIAV 2017 :: GLOCAL [codificar, mediar, transformar, vivir] http://dx.doi.org/10.4995/ANIAV.2017.5828

Sus tareas son:

1. La reconstrucción y fortalecimiento del tejido económico de los sectores culturales y creativos

2. La democratización de la participación cultural mediante la conexión con el ecosistema educativo y la promoción de la igualdad de género.

3. La internacionalización y proyección exterior de la cultura y la creatividad valenciana.

4. La territorialización, integración y descentralización de las dinámicas culturales y creativas, y la normalización de las propuestas en lengua propia.

5. La apertura a nuevos modelos de cooperación y gobernanza de las políticas culturales

\section{CONCLUSIONES.}

La cultura considerada como bien común se aproxima a un modelo didáctico. Como modelo educativo y transformador de la sociedad a futuro, está lleno de potencias. Se presenta como alternativa a las políticas del acceso cuyo objetivo fundamental es permitir el consumo de grandes infraestructuras a la ciudadanía. Frente a la creación de públicos culturales, donde las formas de participación son limitadas, se propone aumentar la participación mediante la puesta en crisis de la idea de consumo. Se plantean indicadores nuevos como la apropiabilidad, contribuir al común, el impacto o la capacidad de transformación.

A corto plazo busca acabar con el "modelo de excelencia" para fundir alta y baja cultura, y poner a profesionales y amateurs al mismo nivel. Sin embargo, romper las barreras de clase puede acarrear la precarización en los procesos de profesionalización lo que podría provocar la imposibilidad de crear un ecosistema sostenible.

El enfoque que se propone desde el PLEC presenta grandes diferencias. Consumidor y productor están claramente diferenciados. La cultura se presenta como un derecho, entendiendo que la ciudadanía es un conjunto de personas a las que proveer de servicios. Se propone que la cultura sea un sector productivo más, no parte del Estado del Bienestar. Sus indicadores de impacto son numéricos y consisten en incrementar el número de trabajadores, espectadores, usuarios, etc. y el gasto público, las producciones audiovisuales competitivas, así como el conjunto del sistema económico.

Según este enfoque, el papel de la cultura es la capacidad para afectar aspectos relacionados con la salud, la educación y la inclusión social o transmitir valores positivos como democracia, sostenibilidad ambiental e igualdad de género. Comunicar, con el objetivo prioritario de "cambiar una imagen valenciana deteriorada", es una especie de diplomacia cultural orientada a satisfacer un interés político diseñado verticalmente. La valoración de la cultura en términos de rentabilidad económica, pone en riesgo la libertad de los creadores, al tiempo que prima a las grandes empresas frente a los autónomos, siendo éstos mayoritariamente trabajadores del arte.

\section{FUENTES REFERENCIALES.}

Raussell, P. (2017). PROPOSTES PROGRAMÀTIQUES PER A UN PLA ESTRATÈGIC DE LA CULTURA, 106. http://www.uv.es/econcult/DCAP.pdf

Rowan, J. (2016). Cultura libre de Estado (Traficante). Madrid: lemur Lecturas de Máxima Urgencia. https://www.traficantes.net/sites/default/files/pdfs/LEM7_cultura\%20libre\%20de\%20Estado.pdf 